\title{
Pre-service teachers' application of understanding by design in lesson planning
}

\author{
Ricardo Lumbreras, Jr. ${ }^{1}$, William H. Rupley ${ }^{2}$ \\ ${ }^{1}$ Department of Curriculum and Instruction, Tarleton State University, United States \\ ${ }^{2}$ Department of Teaching, Learning, and Culture, Texas A\&M University, United States
}

\begin{tabular}{|c|c|}
\hline Article Info & ABSTRACT \\
\hline Article history: & This study focused on preservice secondary teacher's use of the \\
\hline Received Jan 21, 2020 & Understanding by Design (UbD), framework to create effective, engaging \\
\hline Revised Apr 13, 2020 & secondary pre-service secondary education maiors at a Texas University who \\
\hline Accepted Jul 15, 2020 & $\begin{array}{l}\text { were enrolled in a required course for admission into the teacher education } \\
\text { program. Pre-posttest surveys of lesson knowledge design were administered }\end{array}$ \\
\hline Keywords: & $\begin{array}{l}\text { to all subjects. Comparing pre- posttest results revealed that knowledge of } \\
\text { lesson design showed improvement and knowledge gain in the following }\end{array}$ \\
\hline $\begin{array}{l}\text { Backward design } \\
\text { Effective teaching }\end{array}$ & $\begin{array}{l}\text { areas: concepts and vocabulary; unpacking standards; use of verbs from the } \\
\text { standards; rigor; content objectives; formative assessment and summative } \\
\text { assessment. The analyses made use of descriptive statistics and descriptions. }\end{array}$ \\
\hline
\end{tabular}

This is an open access article under the CC BY-SA license.

Preservice teaching learning

Student achievement

Understanding by design

\section{Corresponding Author:}

Ricardo Lumbreras, Jr.,

Department of Curriculum and Instruction,

Tarleton State University,

1333 W. Washington, Stephenville, TX 76402, United States.

Email: lumbreras@tarleton.edu

\section{INTRODUCTION}

Multiple researchers [1-3] have reported that K-12 educators who have received extensive and systematic teacher training and support are often receiving that training from instructors in higher education who have received comparatively little to no instruction in course design. Recent publications [4-9] have attempted to educate higher education faculty about the use of theories and processes of backward design and their impact on learner-centered teaching practices. The backward design method is also referred to as Understanding by Design (UbD) and has become an effective planning strategy for achieving results-based, student-centered learning. Too often, in this age of accountability, learning improvement teams focus on raising academic scores based on external high-stakes assessments [10]. Researchers Wiggins and McTighe [11] propose using a three-stage backward design process that focuses on 1) identifying desired results, 2) analyzing multiple sources of data, and 3) determining an appropriate action plan to achieve the predetermined desired results. Backward course design requires instructors to consider "unpacking standards" that reveal fundamental ideas within learning concepts to develop central questions that students need to authentically demonstrate mastery [12]. Such an approach allows educators to view the concepts through multiple lenses that reveal both students' acquisition of explicit as well as often understated content learnings.

Loeb, Dynarski, McFarland, Morris, Reardon, \& Reber [13] suggest educators need to identify casual relationships in education to understand what works. This study focuses on descriptive statistics and descriptors and seeks to answer questions about who, what, where, when, and to what extent by utilizing 
descriptive analyses as a means to simplify the data. When stakeholders at national, state, and local levels, as well as practitioners make "good decisions" about how to improve education they are often based on these descriptive analyses that enlighten them about the casual understanding they had about a phenomena moving towards a more concrete understanding of that same phenomena.

According to the Organization for Economic Co-operation and Development [14], educators need tools that will increase students' engagement in the learning process and ensure that they are obtaining skills that are demanded in the global economy. These tools should be founded on the OECD goals [14], which are the four C's: communication, collaboration, creativity, and connectedness. Backward design is a model of planning that spearheads engagement and achievement by school planners and educators. Furthermore, Understanding by Design (UbD) has been reported to be a model of planning that puts those four C's, including critical thinking at the forefront of instructional delivery [1, 15].

Backwards lesson design calls for educators to begin with a nominal list of essential questions gathered from the before mentioned unpacking standard step that students must answer by the end of a unit [16]. With this end in mind teachers then design assessments aligned with the concepts and are similar to previously assessed questions, which will provide the framework for the delivery of carefully crafted lessons. The desired outcome is to have rigorous, engaging lessons which are aligned with the concepts and the assessments. Ideally, activities mirror the assessed skills and goals of the unit while maintaining rigor and fairness. Both beginning and veteran educators often forget what it is like to be a novice learner, thus this process of backward design allows for the type of planning that ensures instruction is both aligned to the curriculum and focused on students going deep and not wide during their learning experiences [10].

Backward course design is a simple, rational and structured framework for student-centered learning. It allows the teacher to become a facilitator, who can identify the critical proficiencies that students need to develop, while simultaneously finding authentic ways for them to demonstrate their learning, via the varied and engaging lessons created to rigorously align with the curriculum. Reynolds and Kearns [1] suggest other benefits include content delivery prioritization to students; time management efficacy; lecture delivery improvement; anxiety reduction; creativity increase of idea solutions; and engaged students who offer greater feedback about their comprehension.

For the purposes of this research deep is defined as the complementary area between knowledge, cognition, and values. Based upon the Bloom's Revised Taxonomy Model [17], knowledge is leveled by factual, conceptual, procedural, and metacognitive, each of which has a cognitive process dimension of remember, understand, apply, analyze, evaluate, and create [18]. Value dimensions are viewed as a sense of place and connectedness, responsibility and understanding within the human community [19] and as such should enhance students' engagement in and evaluation of learning [15]. A systematic and manageable instructional implementation and assessment plan based on knowledge, cognitive process, and value dimensions has been found to increase both effectiveness and reduce anxiety for the teacher/instructor [1].

Arriving at the before mentioned destination requires an understanding of the typical approach to curriculum development and lesson design. Albilehi, Young-Han, and Desmidt [20] define curriculum development as a term frequently used in education. However, who curriculum developers are, and their role is under debate. While districts encourage teachers to participate in the development of this curriculum because of their practical experiences in the classroom, they often lack the theoretical framework to interpret their experiences so that they can take ownership and control of their teaching. Carl [21] suggests that curriculum development is not something done to teachers, but through and with them.

Shawer [22] adds insights to how curriculum impacts the instructional approaches educators may use the: 1) fidelity approach where educators transmit the curriculum as is; 2) adaptation approach, in which educators make adjustments and adaptations to existing curriculum; and 3) enactment approach, in which educators view the curriculum as a creation in action. Pre-service educators need to be made aware of these approaches if only to help them understand the basis of each in their instructional decision-making. The fidelity approach can be viewed as prefabricated and not uniquely adapted to the students and the enactment approach is best characterized with the analogy of flying by the seat of your pants. An adaption approach is characterized by creating, negotiating, and renegotiating the concepts, skills, and materials missing in the official curriculum and most closely resembles the principles of backward design [20].

\section{RESEARCH METHOD}

This study was carried out via action research. Multiple authors [23-25] report action research studies are administered in order to diagnose a question about education and to develop solutions or answers to those questions with the expressed intent of shaping and improving educational practices through the collected data. It is in this respect, that the instrumented research plan was put into action in examining teacher and student fidelity and understanding regarding UbD and its impact on student understanding.

Pre-service teachers' application of understanding by design in lesson planning (Ricardo Lumbreras, Jr.) 
The participants $(n=69)$ consisted of 34 males, 35 females who were declared secondary preservice educators, holding a Junior status, and who had not been admitted into the teaching training program at the cooperating university. This study took place during the fall 2018 semester, across two sections of the course, with a response rate of 93 percent.

\subsection{Instrumentation}

Instrumentation used in this study was the result of a researchers' developed survey based on the major characteristics of UbD and course desired outcomes. The content of the survey was validated by four professors, with expertise in curriculum and instruction. The survey consisted of six questions and had a sliding scale response format that ranged from 1 to 5 (1: Strongly disagree, 5: Strongly agree). The validation process included sending out the survey questions to four terminally degreed educators with concentrations in curriculum and instruction for validation, receiving feedback, correcting/clarifying the questions, and resending out again for validation. Level of agreement for the validation process was unanimous and was based on a reciprocal process intended to create a survey that was not only valid but aligned with the content of the course and intent of the research.

\subsection{Research question and supporting statements}

The purpose of this study was to discern what kind of change Understanding by Design made on pre-service teachers' perceptions and vocabulary use while designing educational lessons for their students. The research question is as follows: How are secondary pre-service teachers' perceptions about lesson planning, design, and delivery influenced by the Understanding by Design philosophy? This question was researched by defining the six characteristics the course competencies called for and how they related to UbD. Those characteristics were written as statements that students responded to in a pre-survey the first day of class, and a post-survey in week nine of the course after exposure, instruction, and practice utilizing the UbD framework to create learning objectives and engaging lessons. The statements are as follows:

a. Statement One: I understand the importance of unpacking a standard

b. Statement Two: I understand the relationship between action words in TEKs and identifying results

c. Statement Three: I understand the relationship between backward design and rigor

d. Statement Four: I understand the relationship between assessment and lesson design

e. Statement Five: I understand the relationship between content objectives and lesson delivery

f. Statement Six: I understand the importance of formative assessments during lesson delivery

\subsection{Procedures}

The survey was administered in two sections of the same course taught by the first author. Administration of the survey began with a verbal description of what to do, how to access the survey (QR code), related directions of answering the question (a scale of 1 to 5 - where 1 was strongly disagree and 5 was strongly agree), and finally a choice to participate or not participate in the survey, as well as the statement of assured confidentiality. After survey completion of the pre and post surveys results were analyzed utilizing descriptive statistics gathered from the Qualtrics Survey Tool.

\section{RESULTS AND DISCUSSION}

$\mathrm{UbD}$ is the framework from which major concepts of lesson design were taught in the course. Concepts and vocabulary, unpacking standards, utilizing the verbs from the learning standards, rigor, content objectives, formative assessment and summative assessment were all incorporated into the framework. Statement one concerns itself with unpacking a standard, which is taught as the first step in UbD. Students are taught to ask themselves the following questions when examining a standard to teach: "What is the verb in the standard I am teaching?"; "What is the verb asking me to do?"; "What information do I need to adequately address (including what is explicitly stated and the underlying information therein)?" Unpacking the standard is a critical step in backward design. Because, if you do not know what is required of you to teach, how can you design a lesson or an assessment that targets the skills?

The pre-survey results are displayed in Table 1 and suggest an acquaintance with the concept and terms, but not the deep understanding and skills required to deliver effective and engaging instruction. The post-survey results in Table 2 reveal an increased mean, a decreased standard deviation and variance signifying that the before mentioned deeper understanding and applicability has developed. While it is widely accepted that correlation does not lead to causation, these descriptive statistics support students' growth within the students. Furthermore, effectiveness of group instruction is often associated with a reduction of variance within the group [10]. 
Table 1. Pre-survey study findings

\begin{tabular}{cccc}
\hline Variable & Mean & Standard Deviation & Variance \\
\hline Statement 1 & 2.04 & 1.18 & 1.40 \\
Statement 2 & 2.31 & 1.12 & 1.25 \\
Statement 3 & 1.92 & 1.38 & 1.91 \\
Statement 4 & 3.08 & 1.17 & 1.38 \\
Statement 5 & 3.26 & 1.17 & 1.38 \\
Statement 6 & 2.71 & 1.31 & 1.70 \\
\hline
\end{tabular}

Table 2. Post-survey study findings

\begin{tabular}{cccc}
\hline Variable & Mean & Standard Deviation & Variance \\
\hline Statement 1 & 4.64 & 0.67 & 0.45 \\
Statement 2 & 4.61 & 0.59 & 0.35 \\
Statement 3 & 3.61 & 0.86 & 0.74 \\
Statement 4 & 4.36 & 0.71 & 0.51 \\
Statement 5 & 4.61 & 0.64 & 0.40 \\
Statement 6 & 4.11 & 0.94 & 0.88 \\
\hline
\end{tabular}

Statement two addresses the relationship between the TEKs (Texas Essential Knowledge and Skills) and the expected results of teaching the TEK. TEKs are the competencies students are expected to master in their respective grade levels. The relationship as described in the course is to identify what category the verb (i.e. action word) falls into: Evaluation, Synthesis, Analysis, Application, Comprehension, or Knowledge [26]. Once that is accomplished, identifying results entails examining how this skill has been assessed in the pass, and how it can be assessed in the present via well thought out, engaging lessons. A comparison of Pre-survey results (see Table 1) and Post-Survey results (see Table 2) offer encouragement. As the mean increased, the standard deviation and variance decreased signifying a greater grasp and applicability of the desired skills.

Statement three alludes to the understanding of rigor in the classroom. Paige, et al. [27] suggest that rigor is now viewed as an independent variable that can be intentionally manipulated by the educator, within a range of learning activities (lecture, reading, problem solving, writing, group work, class discussions, presentations, problem-based learning, math, as well as innumerable academic activities) that Schlechty [28] calls knowledge work. This definition addresses four dimensions of rigor; a continuum of cognition (i.e. thinking) ranging from simple to complex; a quantification of rigor in the classroom; it places knowledge work at the end of the continuum so that more complex cognitive thinking can be scaffolded; finally, rigor is intentionally manipulated to encourage growth from simple to complex thinking in students. As a result, rigor is defined as "the extent to which the knowledge work engaged in by students requires cognitive simplicity-complexity" [27].

This relationship between backward design and rigor proved difficult to map during course delivery. The intent was to help the pre-service teachers understand that in unpacking and identifying desired results "rigor" would naturally occur because they would create engaging, collaborative lessons aligned with past assessments that targeted the desired skill. Instead, they associated rigor with length and complexity, with little regard for students' abilities. Instead, they associated rigor with cooperation or passive engagement. Hence, the results from the pre-survey (see Table 1) and the post-survey (see Table 2) do not demonstrate the same kind of growth found in the other concepts.

In this framework, the relationship between assessment and lesson design goes beyond rigor and alignment. It is a question of fairness to the student. If students are going to be assessed locally at the classroom level using the districts' assessments and benchmarks, and also at the state level using standardized tests, then it tracks that what is taught should not only be aligned, but essential to the skills needed to pass the assessments. Teachers can ill afford to teach skills that are not needed or go so far beyond the competency that the results on the exams lower self-esteem for the student. Aligning the assessment with the designed lessons is critical to student success. Jones et. al. [16] suggest that after unit goals and assessments have been created, teachers must design those engaging and enriching lessons that meet both the unit and lesson objectives. To that end, the data supports that students who participated in the research study internalized the concepts (see Table 1 and Table 2 for a comparison of pre and post assessment results).

Content objectives and lesson delivery encompass statement five. Content objectives are the roadmap of lesson delivery. They tell the student what to expect and the instructor what needs to be accomplished by the end of the lesson. Baecher, Farnsworth, and Ediger [26] support this idea as they suggest the development of learning objectives as part of lesson planning is one way of identifying what the focus of a lesson should be and sets out to achieve.

Multiple researchers [29-33] discuss lesson planning as pedagogical reasoning that reflects the teachers' experiences as not only learners, but teachers. Knowledge of their classroom pupils, pedagogical content knowledge, and theories about learning can and often do result in that planning and the plan itself exposing their beliefs, understandings, and orientations. This is critical because educators tend to teach the way they were taught. This dynamic is a major discussion in the course because often pre-service educators need this paradigm shift in their thinking from one of transmitter of facts to facilitator of knowledge. Consequently, the data reported in Table 1 and Table 2 support that students grasp the larger implications for these actions and the importance of implementing them in their classrooms.

Pre-service teachers' application of understanding by design in lesson planning (Ricardo Lumbreras, Jr.) 
Formative assessments differ from summative assessments in that they occur during instruction. Keeley [34] believes an important feature of the assessment-centered classroom is the assessment supports learning by providing students with opportunities to revise and improve their thinking. Often, this occurs during what educators describe as active supervision. Multiple researchers [35-37] report that active supervision has been shown to positively impact student behavior, produced a classroom-wide decrease in minor behavioral incidents, and resulted in higher levels of active participation. Furthermore, it is the degree of active supervision and not the teacher to student ratio that accounted for the greatest variance in nonclassroom transition settings. While the scope of formative assessment strategies is beyond the parameters and capabilities of the course and this report, the techniques of checking for understanding and building relationships with students were major cornerstones of the UbD framework. Keeley [34] suggests there are four classroom environments that support formative assessment:

a. A learner-centered environment where teachers pay careful to the knowledge, beliefs, attitudes and skills of their students.

b. A knowledge-centered environment where teachers know the goals, key concepts, ideas, and prerequisites for learning.

c. An assessment-centered environment where students are able to revise and improve their thinking while monitoring their own learning.

d. A community-centered environment where students learn from each other and continually strive to improve their learning.

The goal according to Keeley [34] to create a classroom ecosystem where these four environments overlap and both students and teachers feel part of the intellectual learning community that is constantly growing and improving with regards to teaching and learning. Accordingly, the data reported in Table 1 and Table 2 support that students internalized these beliefs and see the importance of both in their classrooms.

\section{CONCLUSION}

The UbD framework (and subsequent rationales) presented in this study seek to help pre-service educators feel better prepared across most dimensions of teaching. Teacher quality, qualified teachers, and effective teachers are the goal of learning this framework. That said, there are several important limitations that should be noted with this research report.

First, is the topic of UbD and how it was used as the framework for lesson planning, lesson design, and lesson delivery. Different educators, from different content areas, resonate differently with multiple tools and approaches that work for them because of their preferred style. It is that vein of thinking that UbD was utilized in this way, for this content delivery, in this pre-service educator course. Second, survey results were analyzed using descriptive statistics. The survey was not designed to utilize inferential statistical analysis or non-parametrical statistical procedures. As such, violations of normality were not analyzed. Third, this was a sample of convenience, which limits generalizability. The population could be deemed homogeneous (preservice educators) whose perceptions and opinions were skewed (to the positive) because of the emphasis put upon the UbD framework in the course.

Finally, a qualitative component is needed to further explore pre-service teachers' definition and understanding of these concepts. Contradictions and areas of conflict or misunderstandings are not measurable without it. The pedagogical requirements that teacher education programs ask of their pre-service teachers necessitate a new way of delivering course content related to lesson planning, design, and delivery. It is anticipated that this framework can continue to be used for the before mentioned purposes, while simultaneously implementing qualitative and inferential statistical analysis to discern and describe the individual responses and opinions of the framework.

\section{REFERENCES}

[1] H.L. Reynolds and K.D. Kearns, "A planning tool for incorporating backward design, active learning, and authentic assessment in the college classroom," College Teaching, vol. 65, no. 1, pp. 17-27, 2017.

[2] D.H. Wulff, A.E. Austin, J.D. Hyquist, and J. Sprague, "The Development of Graduate Students as Teaching Scholars: A Four-Year Longitudinal Study," in Paths to the Professoriate: Strategies for Enriching the Preparation of Future Faculty, D.H. Wulff \& A.E. Austin, Eds., pp. 46-74, 2004.

[3] C.M. Golde and T.M Dore, "At Cross Purposes: What the Experiences of Today's Doctoral Students Reveal about Doctoral Education: A Survey Initiated by the Pew Charitable Trusts," Philadelphia: A report prepared for the Pew Charitable Trusts, 2001.

[4] K.K. Daugherty, "Backward course design: Making the end the beginning," American Journal of Pharmaceutical Education, vol. 70, no. 6, pp. 1-5, 2006.

[5] E.L. Dolan and J.P. Collins, "We must teach more effectively: Here are four ways to get started," Molecular Biology of the Cell, vol. 25, no. 12, pp. 2151-2155, 2015. 
[6] W.B. Wood, "Innovations in teaching undergraduate biology and why we need Them," Annual Review of Cell and Developmental Biology, vol. 25, no. 5, pp. 93-112, 2009.

[7] L.A. Baker, et al., "Collateral scholars' collaborative new faculty workshop: Professional development for new chemistry faculty and initial assessment of its efficacy," J. of Chem. Educ., vol. 91, no. 11, pp. 1874-1881, 2014.

[8] D. Ebert-May, et al, "What we say is not what we do: Effective evaluation of faculty professional development programs," BioScience, vol. 61, no. 7, pp. 550-558, 2011.

[9] K. Trigwell, "Promoting Effective Student Learning in Higher Education," in International Encyclopedia of Education 4, P. Peterson, E. Baker, and B. McGaw, Eds. Oxford: Elsevier, pp. 461-466, 2010.

[10] W. Au, "High stakes testing and curricular control: A qualitative metasynthesis," Educational Researcher, vol. 36, no. 5, pp. 258-267, 2007.

[11] G. Wiggins and J. McTighe, Understanding by design. Alexandria, VA: ASCD, 1998.

[12] J. McTighe and R.S. Thomas, "Backward design for forward action," Educational Leadership, vol. 60, no. 5, pp. 52-55, 2003.

[13] S. Loeb, et al., "Descriptive analysis in education: A guide for researchers" (NCEE 2017-4023). Washington, DC: U.S. Department of Education, Institute of Education Sciences, National Center for Education Evaluation and Regional Assistance, 2017. [Online]. Available: https://files.eric.ed.gov/fulltext/ED573325.pdf

[14] Organization for Economic Co-operation and Development, "Trends shaping education," 2013. [Online]. Available: http://www.oecd.org/education/eag2013\%20(eng)--FINAL\%2020\%20June\%202013.pdf

[15] T.P. Florian and J.P. Zimmerman, "Understanding by design, moodle, and blended learning: A secondary school case study," MERLOT Journal of Online Learning and Teaching, vol. 11, no. 1, pp. 103-111, 2015.

[16] K.A. Jones, P.J. Vermette, and J.L. Jones, "An integration of backwards planning unit design with the two-step lesson planning framework," Education, vol. 130, no. 2, pp. 357-360, 2009.

[17] D. Krathwohl and L. Anderson, "Merlin C. Wittrock and the Revision of Bloom's Taxonomy," Educational Psychologists, vol. 45, no. 1, pp. 64-65, 2010.

[18] W. Huitt, "A holistic view of education and schooling: Guiding students to develop capacities, acquire virtues, and provide service," Revision of paper presented at the $12^{\text {th }}$ Annual International Conference sponsored by the Athens Institute for Education and Research (ATINER), May 24-27, 2011. [Online]. Available: http://www.edpsycinteractive.org/papers/holistic-view-of-schooling-rev.pdf

[19] H.L. Reynolds, "Overview: Core Learning Goals for Campus-Wide Environmental Literacy," in Teaching Environmental Literacy: Across Campus and Across the Curriculum, H.L. Reynolds, E.S. Brondizio, and J.M. Robinson, Eds. Bloomington, IN: Indiana University Press, pp. 17-27, 2010.

[20] R. Albilehi, J. Young-Han, and H. Desmidt, "Curriculum development 101: Lessons learned from a curriculumdesign project," The Catesol Journal, vol. 24, no. 1, pp. 187-197, 2012-2013.

[21] A. Carl, Teacher empowerment through curriculum development: Theory into practice. Cape Town. South Africa: Juta, 1995.

[22] S. Shawer, "Classroom-level curriculum development: EFL teachers as curriculum-developers, curriculum-makers and curriculum-transmitters," Teaching and Teacher Education, vol. 26, no. 2, pp. 173-184, 2010.

[23] L. Berg, Qualitative research methods for the social sciences. London, UK: Pearson Education, Inc., 2001.

[24] A. Burns, Doing action research in English language teaching: A guide for Practitioners. London \& New York: Routledge, 2010

[25] J.W. Creswell, Educational research: Planning, conducting, and evaluating quantitative and qualitative research. Massachusetts, MA: Pearson Education, Inc., 2012.

[26] H.K. Wong and R.T. Wong, The first days of school: How to be an effective teacher. Mountain View, CA: Harry K. Wong Publications, 2009.

[27] D.D. Paige, G.S. Smith, and J.M. Sizemore, "Conceptualizing rigor and its implications for education in the era of the common core," Cogent Education, vol. 2, no. 1, pp. 1-10, 2015.

[28] P. Schlechty, "Creating the capacity to support innovations," Occasional Paper, no. 2, pp. 1-24, 2005. [Online]. Available: http://schlechtycenter.org

[29] L. Baecher, T. Farnsworth, A. Ediger, "The challenges of planning language objectives in content-based ESL instruction," Language Teaching Research, vol. 18, no. 1, pp. 118-136, 2013.

[30] B. Ho, "Using lesson plans as a means of reflection," ELT Journal, vol. 49, no. 1, pp.66-71, 1995.

[31] P.D. John, "Course, curricular and classroom influences on the development of student teachers' lesson planning perspectives," Teaching and Teacher Education, vol. 7, no. 1, pp. 359-373, 1991.

[32] P.D. John, "The integration of research validated knowledge with practice: Lesson planning and the student history teacher," Cambridge Journal of Education, vol. 24, no. 1, pp. 33-49, 1994.

[33] LL. Warren, "Teaching planning: A literature review," Educational Research Quarterly, vol. 24, no. 1, pp. 37-42, 2000.

[34] P. Keeley, Science Formative Assessment: 75 practical strategies for linking assessment, instruction, and learning. Thousand Oaks, CA: Corwin/NSTA Press, 2008.

[35] B. Simonsen, S. Fairbanks, A. Briesch, D. Myers, G. Sugai, "Evidence-based practices in classroom management: Considerations for research to practice," Education and Treatment of Children, vol. 31, no. 3, pp. 351-380, 2008.

[36] J.M. Schuldheisz and H. van der Mars, "Active supervision and students' physical activity in middle school physical education," Journal of Teaching in Physical Education, vol. 21, no. 1, pp. 75-90, 2001.

[37] G. Colvin, G. Sugai, R.H. Good Ill, and Y-Y Lee, "Using active supervision and pre-correction to improve transition behaviors in an elementary school," School Psychology Quarterly, vol. 12, no. 1, pp. 344-361, 1997. 